\title{
Synthesis and properties of carbon nanospheres grown by CVD using Kaolin supported transition metal catalysts
}

\author{
Jian-Ying Miao, Dennis W. Hwang, Kuppala V. Narasimhulu, Ping-I Lin, \\ Yit-Tsong Chen, Sheng-Hsien Lin, Lian-Pin Hwang * \\ Institute of Atomic and Molecular Sciences, Academia Sinica and Department of Chemistry, National Taiwan University, \\ Roosevelt Road, Taipei 10617, Taiwan
}

Received 22 January 2003; accepted 15 January 2004

\begin{abstract}
Carbon spheres with diameters between 400 and $2000 \mathrm{~nm}$ were synthesized in large quantities by catalytic chemical vapor deposition (CCVD) method using Kaolin supported transition metal salts ( $\mathrm{M}=\mathrm{Fe}, \mathrm{Co}$, Ni, etc.) as catalysts. The reaction conditions for the synthesis of carbon spheres in different sizes are described. The reactivity of the carbon spheres in various organic solvents is discussed. The as-synthesized carbon spheres are composed of unclosed graphene layers with the interlayer distances $0.33-0.35 \mathrm{~nm}$. These carbon spheres have been characterized by SEM, TEM, HRTEM, XRD, Raman, ESR and SQUID magnetization techniques. From the ESR and SQUID the metallic nature of the carbon spheres is described.
\end{abstract}

(C) 2004 Elsevier Ltd. All rights reserved.

Keywords: A. Catalytically grown carbon, Vapor grown carbon; B. Catalyst support, Chemical vapor deposition; C. Electron microscopy, Electron spin resonance, Raman spectroscopy; D. Magnetic properties

\section{Introduction}

The ease of processing and forming of light materials may be one of the main reasons for the rapidly growing applications of carbon structures. Carbon nanomaterials may be useful material in spark gap and corona eliminating terminations. These are desirable materials where high current arcing is involved since they do not melt or develop pits or projections, but tend to remain smooth. Such lightweight structures with high strength and stiffness are expected to find applications in both spacecraft components and aircraft braking. The various forms of carbon structures were well reviewed by Harris [1] taking into account the research results reported before. In brief, carbon onions were reported first by Iijima in 1980 [2]. Fullerenes were also reported as a product by vaporizing carbon from a rotating disk of graphite using a focused laser in a helium flow in 1985 [3]. However, after Iijima reported the discovery of nanotubes using a high-resolution transmission electron microscope (HRTEM) [4] in 1991, a great deal of re-

\footnotetext{
${ }^{*}$ Corresponding author. Tel.: +886-2-23668287; fax: +886-223620200

E-mail address: nmra@po.iams.sinica.edu.tw (L.-P. Hwang).
}

search was excited. After that, more and more forms of carbon, such as fullerenes [5,6] $\mathrm{C}_{n}$ family [7], carbon nanotubes [8-11], carbon nanofibers [12,13], carbon onions [14-19], carbon trees [20,21], carbon spheres [2227], ordered mesoporous carbons [28], carbon capsules [29] and carbon nanowalls [30], have been synthesized and studied by scientists around the world. Recently, a very few papers on metal dispersed carbon spheres synthesized using the chelate resins were also reported [31-33].

Carbon spheres with different structure from the $\mathrm{C}_{60}$ cage and carbon onions have unclosed graphene layers. Compared to the studies of fullerenes, carbon nanotubes and nanofibers, reports on the research of carbon spheres are relatively few in number. Carbon spheres have similar properties to graphite or fullerene, which allows them to fabricate diamond films, lubricating materials and special rubber additives. However, an economic method of preparing large amount of carbon spheres under reasonable experimental conditions is still lacking to date.

Graphite, has a 3-fold coordinated $\mathrm{sp}^{2}$ hybridization forming strong intra-layers bonding within the hexagonal carbon-rings, and a weakly unsaturated $\pi$-bonding with adjacent layers perpendicular to the hexagonal 
network, in contrast to diamond. $\mathrm{C}_{60}$ is considered to be chemically inert because of the weakly unsaturated $\pi$ bonding normal to the surface. Carbon spheres of microcrystalline graphite layers can be synthesized by using transition and/or rare earth metal oxides as catalysts with mixed valences at $1100{ }^{\circ} \mathrm{C}$ [34]. These spheres have an average diameter of $\sim 210 \mathrm{~nm}$. Carbon spheres with sizes of $1-10 \mu \mathrm{m}$ were found in carbon black generated from the carbonization of polyethylene-poly(vinyl chloride) in a sealed gold tube under a pressure of $30 \mathrm{MPa}$ [35] and in carbon vapor from the decomposition of $\beta$-SiC powder [36]. Carbon spheres of $20-500 \mu \mathrm{m}$ are found as a side product in the synthesis of fullerene by the deposition of gaseous carbon in flowing helium (33 mbar) at $2500-2600{ }^{\circ} \mathrm{C}$ without catalysis [37]. However, the cost of production in the synthetic methods mentioned above is high and limits production in larger quantities. This has motivated many researchers in carbon structures to try new synthetic methods that allow synthesizing carbon spheres in large quantities at lower costs and at relatively lower temperatures.

The synthesis reaction produces carbon spheres of different sizes even at relatively low temperatures $(\sim 650$ ${ }^{\circ} \mathrm{C}$ ) by transition metal salts supported on Kaolin (hydrated aluminium silicate mineral) catalysts. In this paper, we report the low cost synthesis of carbon nanospheres with detailed reaction conditions, such as reaction times, reaction temperatures and gas flow rates. The as-synthesized carbon spheres were also characterized using different techniques to explore their origin, structure and different physical and chemical properties.

\section{Experiments}

\subsection{Synthesis of carbon spheres}

Transition metal salts $(\mathrm{TM}=\mathrm{Co}, \mathrm{Ni}, \mathrm{Fe})$ (Acros) were dissolved in deionized water. Though, all these TM supported catalysts were synthesized, in this paper we report in detail the synthesis of carbon spheres using cobalt supported Kaolin catalyst only. The Kaolin (Acros) of the same weight as that of transition metal salts was added to the above solution and stirred vigorously for about $10 \mathrm{~min}$. A sample of Kaolin with the size smaller than 100 mesh was used. The slurry was coated on the surface of a Kaolin, or ceramic plate as a thin film, and dried in air at about $60{ }^{\circ} \mathrm{C}$. These thin porous layers of catalyst plate are important in the growth of carbon nanostructures. The catalyst plate was placed on a ceramic boat with face down in the center of a quartz tube in a column furnace. $\mathrm{N}_{2}$ gas was fed into the quartz tube at 100,200 or $300 \mathrm{sccm}$ while the furnace was heating. When the temperature of the furnace surpassed $650{ }^{\circ} \mathrm{C}, \mathrm{C}_{2} \mathrm{H}_{2}$ gas was introduced into the reaction chamber at a rate of $50 \mathrm{sccm}$. After reacting for some time, $\mathrm{C}_{2} \mathrm{H}_{2}$ was stopped and $\mathrm{N}_{2}$ was flowed through the reaction chamber until the temperature of the furnace was lower than $250^{\circ} \mathrm{C}$. Carbon spheres were collected from the ceramic boat beneath the catalyst plate. The same procedure can be adapted to other transition metal catalysts also.

\subsection{Characterization of carbon spheres}

TEM images of the samples were performed using a JEOL JSM-1200 EX II Transmission Electron Microscope. The reacted catalyst was ground and dispersed in 95\% ethanol. The collected carbon spheres were dispersed in $95 \%$ ethanol directly. After being sonicated for more than half an hour, the samples were dropped onto a grid and dried for TEM investigation. SEM images of the carbon spheres were obtained with a VG microlab 350 System. The Auger electron spectrum of the spheres was obtained with the VG microlab 350 System and an elemental analysis of the spheres was conducted in a Philips XL-30 SEM equipped with EDS. The microstructure of the carbon spheres was studied by using a JEOL JEM-4000EX High Resolution Transmission Electron Microscope (HRTEM). Samples were analyzed by X-ray powder diffraction before and after reaction. This test was carried out with a Rigaku D/MAX IIB $\mathrm{X}$-ray diffractometer. The Raman data of the as-synthesized carbon spheres were recorded on a Jobin Yvon T64000 Spectrometer equipped with a charge coupled device (CCD) detector cooled with liquid nitrogen. The backscattering signal was collected with a microscope using an $\mathrm{Ar}^{+}$laser centered at $488 \mathrm{~nm}$ as the excitation source. All the spectra were obtained at room temperature. The ESR spectra of carbon spheres have been recorded on a JEOL FE 1X ESR spectrometer operating at X-band microwave frequency $(\approx 9.201 \mathrm{GHz})$ with a $100 \mathrm{kHz}$ field modulation. The magnetization studies were carried out at three different temperatures, 5, 100 and $300 \mathrm{~K}$ using SQUID (Quantum Design MP MS7).

\subsection{Stability test for the carbon spheres}

The carbon spheres were dropped in HF $(48 \%$, Riedel-deHaën) and stirred for more than $48 \mathrm{~h}$. After filtering and washing with deionized water, the sample was investigated using TEM. One hundred milligrams of the material of the carbon spheres were added to 0.003

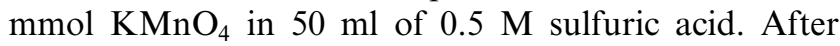
stirring vigorously for $2 \mathrm{~h}$ at $80^{\circ} \mathrm{C}$, the solid obtained by filtering and washing with deionized water was examined by TEM. About $200 \mathrm{mg}$ of as-synthesized carbon spheres were dispersed in $20 \mathrm{ml}$ of carbon disulfide (Riedel-deHaën), 1-methylnaphthalene (Acros, 97\%) or 1,2-dichlorobenzene (Acros, 99\%), respectively. These mixtures were sonicated for more than $1 \mathrm{~h}$. After being 
filtered, the solutions were dropped on a grid and dried for the TEM test.

\section{Results}

\subsection{Synthesis and characterization of pure carbon spheres}

Kaolin plate of approximately $4 \mathrm{~cm} \times 2.5 \mathrm{~cm}$ size was coated with $0.2 \mathrm{~g}$ of $\mathrm{Co} / \mathrm{Kaolin}$ to form a porous thin film on the surface of the plate and dried at $60{ }^{\circ} \mathrm{C} . \mathrm{C}_{2} \mathrm{H}_{2}$ and $\mathrm{N}_{2}$ gases were flown through the Kaolin plate at $650-900{ }^{\circ} \mathrm{C}$ for $1 \mathrm{~h}$ at 50 and $200 \mathrm{sccm}$, respectively. $\mathrm{N}_{2}$ gas was kept flowing until the temperature of the furnace was lower than $250{ }^{\circ} \mathrm{C}$. About $0.3 \mathrm{~g}$ of pure carbon spheres could be collected from the $20 \mathrm{~cm}$ long ceramic boat. So the yield is about 1.5 times that of the catalyst used even at mild temperature ranges $\left(650-700{ }^{\circ} \mathrm{C}\right)$. The catalyst still has catalytic activity and can be reused several times after being retreated at temperatures slightly above $700{ }^{\circ} \mathrm{C}$ in air for $10 \mathrm{~min}$.

SEM and TEM images of the collected products show mono-dispersed carbon spheres without impurities. These carbon spheres have diameters of 400-2000 $\mathrm{nm}$. More than $80 \%$ of the carbon spheres were found to have the sizes of $600-800 \mathrm{~nm}$. Carbon spheres with uniform sizes can be collected from different parts of the collecting boat. Fig. 1a-c show the TEM and SEM images of as-synthesized carbon spheres. Fig. 1d shows the TEM image of the reacted catalyst. Initially, some carbon nanotubes will be formed within first half-anhour of the reaction over the catalyst template. As seen from Fig. 1d, some carbon spheres mingle with carbon nanotubes in the reacted catalyst. However, no carbon nanotubes were found in the collected carbon spheres. Only carbon spheres were deposited on the collecting boat, which placed at the down stream of the catalyst plate. HRTEM images (Fig. 2) show that the solid carbon spheres are composed of uniform unclosed graphene layers with open edges. The distances between graphene layers are about $0.33-0.35 \mathrm{~nm}$, which is similar to the distance between crystal layers of graphite. The collected spheres were analyzed by Auger electron spectroscopy and energy dispersive X-ray spectroscopy. The results indicate that the constituent of the spheres is only carbon and no other elements are found.

XRD patterns of the Kaolin supported catalyst (before and after reaction) and the carbon spheres are shown in Fig. 3. The XRD pattern of Kaolin confirms that it includes several phases. One of them is halloysite. ' $\mathrm{H}$ ' in the XRD pattern of Kaolin refers to the characteristic peaks of halloysite. Kaolin was added to $\mathrm{Co}^{2+}$ salt solution and dried in air at $60{ }^{\circ} \mathrm{C}$ to form the catalyst. The XRD pattern of the catalyst before reaction shows some characteristic peaks of Kaolin. When the XRD pattern of the cobalt impregnated catalyst is compared with the Kaolin, one can easily identify the peaks corresponding to cobalt in the catalyst before reaction. After reaction, the XRD pattern of the ground powder specimen of the catalyst exhibits some weak characteristic peaks of $\mathrm{Co}$. The most prominent peaks in this pattern (reacted catalyst) suggest that the dominant phase of the hexagonal structure of graphite belongs to the carbon nanotubes. In the XRD pattern of collected
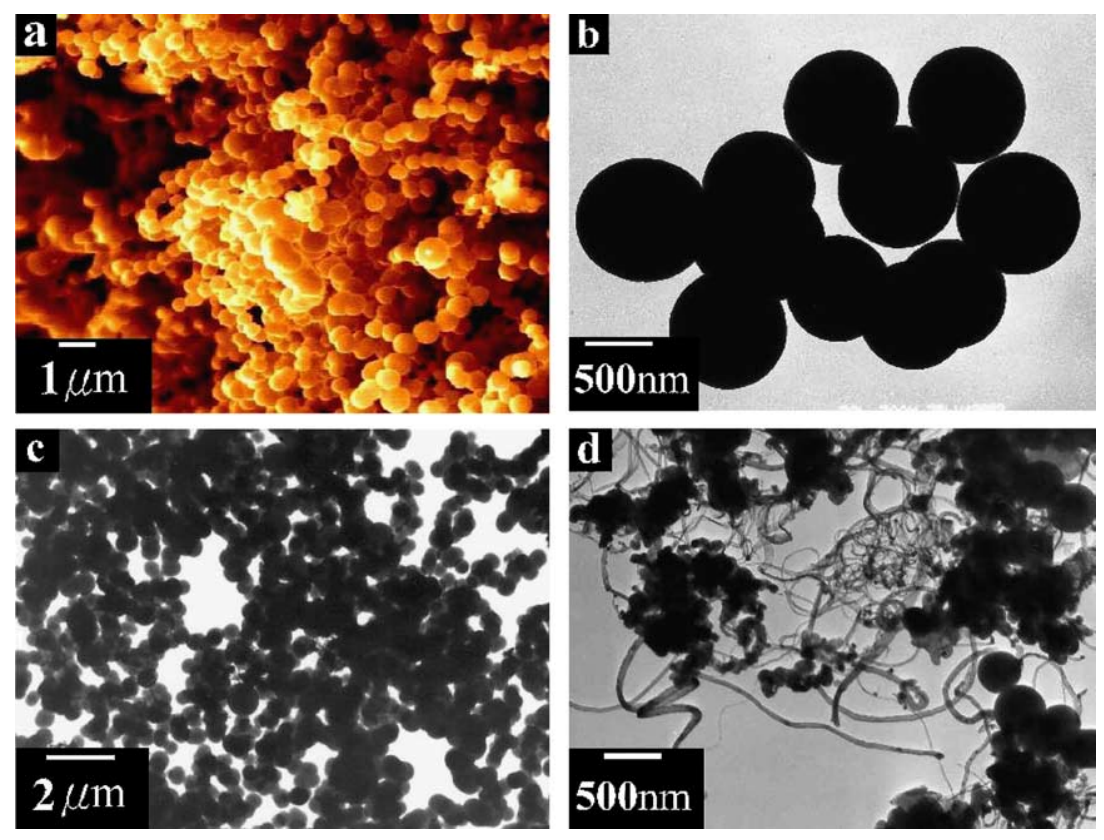

Fig. 1. Electron microscopic images of the products synthesized by Co/Kaolin. (a) SEM image of the collected carbon spheres, (b) and (c) TEM images of the carbon spheres, (d) TEM image of the reacted catalyst. 

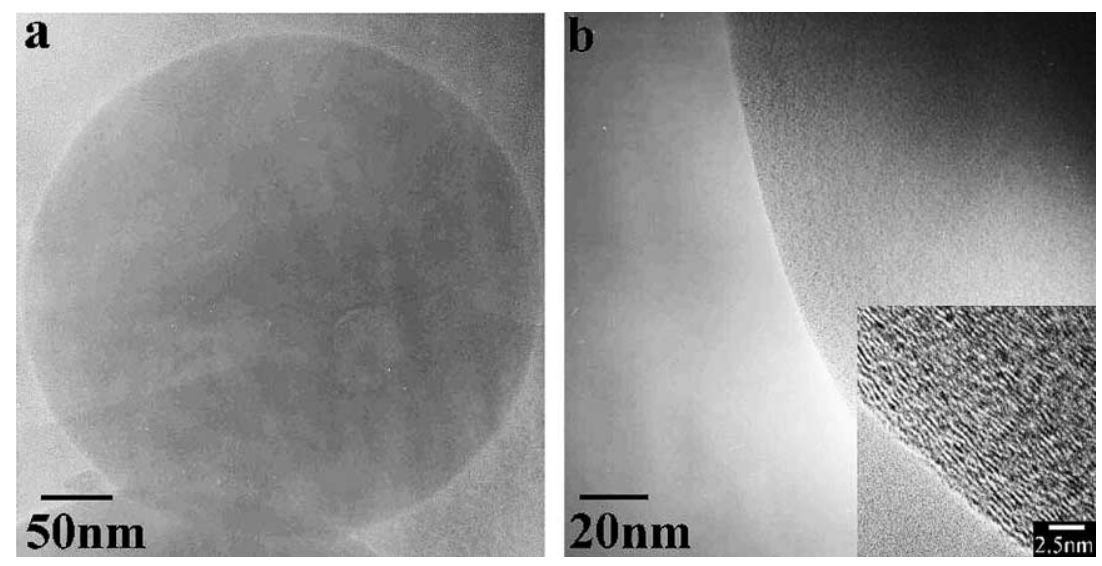

Fig. 2. HRTEM images of a carbon sphere.

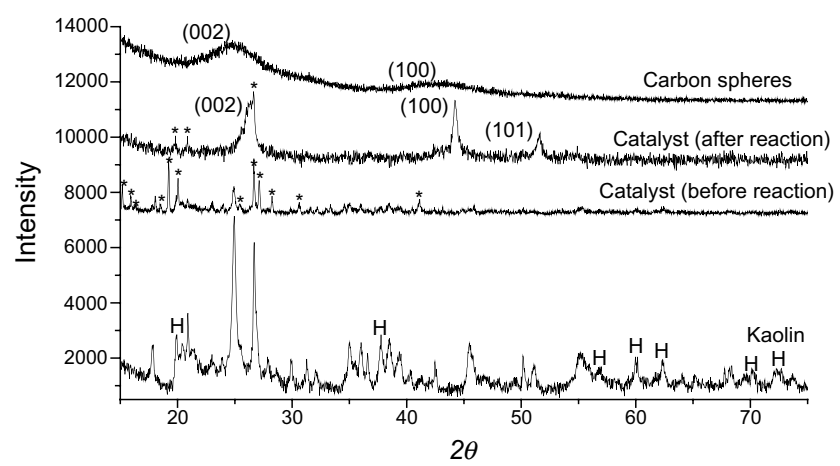

Fig. 3. XRD patterns of the samples where $\mathrm{H}$ represents halloysite and asterisk “*” denotes Co.

carbon spheres, the $\left(\begin{array}{lll}0 & 0 & 2\end{array}\right)$ and $\left(\begin{array}{lll}1 & 0 & 0\end{array}\right)$ peaks are broadened. This peak broadening suggests the possible presence of an amorphous carbon phase within the carbon spheres. HRTEM images reveal that the product contains well-formed carbon spheres. TEM and SEM investigations confirm the absence of the carbon nanotubes in the collected carbon sphere samples.

Raman spectra of carbon spheres with different diameters $(1 \mu \mathrm{m}$ and $500 \mathrm{~nm})$ at ambient temperature and pressure are shown in Fig. 4. The excitation wavelength for the $\mathrm{Ar}^{+}$laser-Raman spectrum is $488 \mathrm{~nm}$. Prominent peaks in the Raman spectra at $\sim 1590$ and $\sim 1360 \mathrm{~cm}^{-1}$ correspond to the $\mathrm{E}_{2 \mathrm{~g}}(2)$ ( $\mathrm{G}$ band) and disorder-induced ( $\mathrm{D}$ band) modes of graphite, respectively, where the latter has much wider bandwidth in the present observation. For the carbon spheres of $\sim 1 \mu \mathrm{m}$, the $\mathrm{D}$ mode and $\mathrm{G}$ band are 1357 and $1591 \mathrm{~cm}^{-1}$; when the diameter of the carbon sphere reduces to $\sim 500 \mathrm{~nm}$, both of them shift slightly towards the blue side to 1358 and $1587 \mathrm{~cm}^{-1}$, respectively. In a previous study on the carbon spheres of $\sim 200 \mu \mathrm{m}$, Loa et al. [37] observed a disorder-induced $\mathrm{D}^{\prime}$ mode at $1622 \mathrm{~cm}^{-1}$ in the Raman spectrum. In the present work, the $\mathrm{D}^{\prime}$ mode, however, is not discerned from the peak of the $\mathrm{G}$ band.
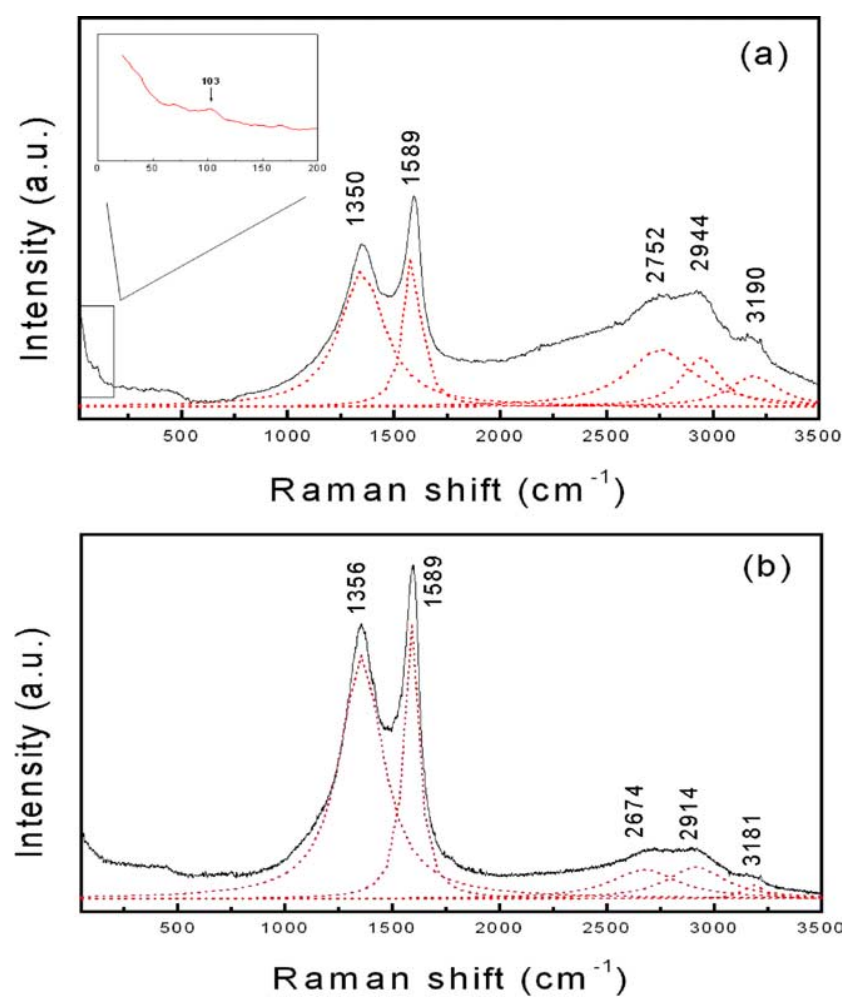

Fig. 4. Raman spectra of as-synthesized carbon spheres: (a) $\sim 500 \mathrm{~nm}$ and (b) $\sim 1 \mu \mathrm{m}$.

Broad bands at $2700-3200 \mathrm{~cm}^{-1}$ have been observed in the Raman spectra of both samples. Three bands at 2674 (2752), 2914 (2944), and 3181 (3190) $\mathrm{cm}^{-1}$ for carbon spheres of $1 \mu \mathrm{m}(500 \mathrm{~nm})$ are obtained after spectral deconvolution (Fig. 4). The bands at 2674 (2752) and $3181(3190) \mathrm{cm}^{-1}$ can be attributed, respectively, to the second-order $\mathrm{D}(2 \times \mathrm{D})$ and $\mathrm{G}(2 \times \mathrm{G})$ modes. The band at 2914 (2944) $\mathrm{cm}^{-1}$ is due to the combination mode of $\mathrm{D}$ and $\mathrm{G}$ bands. The spectral intensities of the $2 \times \mathrm{D}$ bands are much weaker than those of $\mathrm{D}$ bands for carbon spheres of $1 \mu \mathrm{m}$ and $500 \mathrm{~nm}$ in the present observation, in contrast to previous 
reports on carbon spheres of size $\sim 200 \mu \mathrm{m}$ [37]. For carbon spheres of $500 \mathrm{~nm}$, we have observed a weak signal at $103 \mathrm{~cm}^{-1}$ (Fig. 4b), which compares to the $B_{1 \mathrm{~g}}(1)$ mode of $119 \mathrm{~cm}^{-1}$ in the Raman spectrum of 200 $\mu \mathrm{m}$ carbon spheres observed by Loa et al. [37]. The $\mathrm{B}_{1 \mathrm{~g}}(1)$ phonon of graphite, corresponding to a rigid displacement of the graphene sheets perpendicular to the layers, was reported as $126 \mathrm{~cm}^{-1}[38,39]$. In view of the trend that a softer $\mathrm{B}_{1 \mathrm{~g}}(1)$ phonon motion corresponds to larger curvature of the carbon spheres, the "breathing" vibrational frequency of the carbon spheres is expected to be lower in a smaller sphere.

\subsection{Reaction conditions}

\subsubsection{Reaction temperatures and reaction times which control the size of carbon spheres}

$\mathrm{N}_{2}$ and $\mathrm{C}_{2} \mathrm{H}_{2}$ were flowed at 200 and $50 \mathrm{sccm}$ for 1 hour with varying temperatures. The yields of the collected carbon spheres in the boat at 650,700, 750, 800, 850,900 and $950{ }^{\circ} \mathrm{C}$ are about $0.3,0.38,0.58,0.6,0.65$, 0.68 and $0.70 \mathrm{~g}$, for about $0.2 \mathrm{~g}$ of the $\mathrm{Co}^{2+} /$ Kaolin catalyst. Less carbon spheres are formed at temperatures lower than $700{ }^{\circ} \mathrm{C}$. At temperature higher than $900{ }^{\circ} \mathrm{C}$, the highest yield of the carbon spheres was found. However, after the reaction at or above $900{ }^{\circ} \mathrm{C}$, the catalyst is easy to sinter, making the repeated use of the catalyst impossible. Therefore, a temperature between 750 and $850{ }^{\circ} \mathrm{C}$ is suitable for the reaction in order to use the catalyst repeatedly. Reaction temperature, however, hardly affects the sizes of the as-synthesized carbon spheres. Carbon spheres with dimensions of 400-2000 $\mathrm{nm}$ can be obtained in the temperature region $650-850$ ${ }^{\circ} \mathrm{C}$, where most of the carbon spheres have the diameters in the range $600-800 \mathrm{~nm}$.

The carbon spheres and catalyst were first examined at $700{ }^{\circ} \mathrm{C}$ at $5,10,15,20,25$ and $30 \mathrm{~min}$ and then at 1,2 , 3 and $4 \mathrm{~h}$ of reaction. No carbon spheres could be found in the collecting boat for a reaction time less than 15 min. More mono-dispersed carbon spheres can be ob- tained in the collecting boat, when the reaction time is longer than $15 \mathrm{~min}$. The largest quantity of pure carbon spheres were collected after $1-2 \mathrm{~h}$ of reaction. From these observations, it is confirmed that the longer reaction times are better for higher production and the products at the same time are easy to agglomerate into bigger particles. The carbon spheres obtained at suitable reaction times will have the property of soft and light, cotton like material. These particles become harder and harder with extending reaction times. At prolonged reaction times, the product forms as hard sand like layers and the mass of the particles becomes brittle, because they are cemented together due to high temperature annealing. At the end, it is very difficult to separate these hard particles even by grinding or sonication.

During the first $15 \mathrm{~min}$ of the reaction, carbon nanotubes and quasi-spherical carbon shells surrounding the metal-containing particles were found. Particles embedded in the carbon shells were smaller and smaller after reacting 5-15 min. Electron diffraction patterns were obtained for the quasi-spherical carbon shells including the metal-containing particles and the pure carbon spheres. The carbon sphere was amorphous without any crystallized particles in it as seen in Fig. 5a and $b$ at the initial stages of the reactions.

\subsubsection{Flow rates of the gases}

Distribution of the collected carbon spheres depends on the gas flow rates. We have introduced $\mathrm{N}_{2}$ at 100, 200 and $300 \mathrm{sccm}$ into the reaction systems. Carbon spheres with uniform sizes can be collected every $1-2 \mathrm{~cm}$ in the ceramic boat while the $\mathrm{N}_{2}$ gas flow is at $200 \mathrm{sccm}$ (see Fig. 6a). However, the carbon spheres could not be separated from the other spheres even at $100 \mathrm{sccm}$ of $\mathrm{N}_{2}$ flow. Various sizes of carbon spheres are mixed up as shown in Fig. 6b. If the flow rate of $\mathrm{N}_{2}$ is $300 \mathrm{sccm}$, most of the carbon spheres are blown away from the boat and even out of the quartz tube furnace. The flow rate of
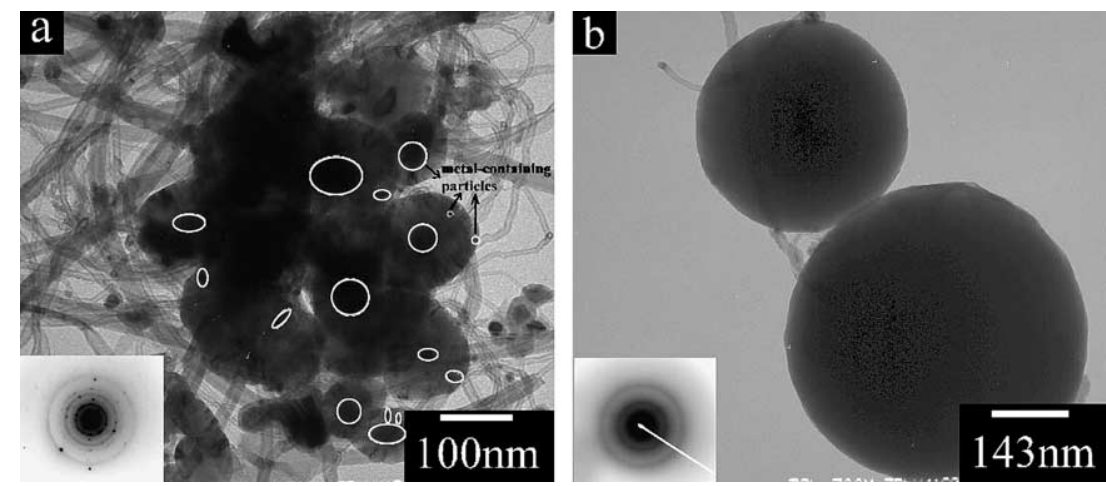

Fig. 5. TEM images and electron diffraction patterns of the catalyst and the carbon sphere after reaction for 10 and 25 min: (a) the catalyst after 15 min reaction, (b) pure carbon spheres collected after 25 min reaction. 

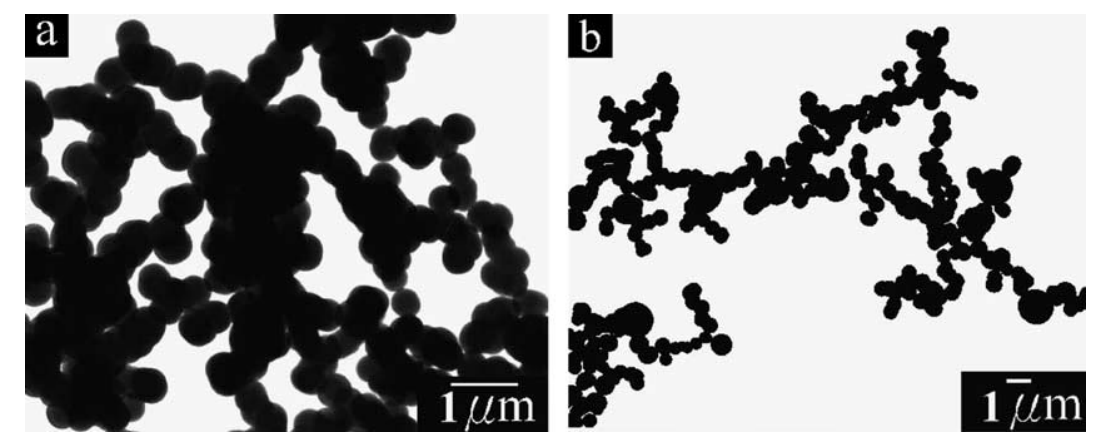

Fig. 6. TEM images of the carbon spheres separated by $\mathrm{N}_{2}$ at 200 and $100 \mathrm{sccm}$ : (a) $200 \mathrm{sccm}$, (b) $100 \mathrm{sccm}$.

$\mathrm{C}_{2} \mathrm{H}_{2}$ has less effect on the separation of the carbon spheres.

Yields of the carbon spheres increase with increasing flow rates of $\mathrm{C}_{2} \mathrm{H}_{2}$ gas. $\mathrm{C}_{2} \mathrm{H}_{2}$ was used at $50 \mathrm{sccm}$ in this reaction. Higher flow rate of $\mathrm{C}_{2} \mathrm{H}_{2}$ was not used in this reaction for the reasons of safety and to avoid the saturation of the $\mathrm{C}_{2} \mathrm{H}_{2}$ gas in the reaction. In practice, $\mathrm{N}_{2}$ and $\mathrm{C}_{2} \mathrm{H}_{2}$ at 200 and $50 \mathrm{sccm}$, respectively, are better for synthesizing and separating the carbon spheres. Further more, the flow of $\mathrm{C}_{2} \mathrm{H}_{2}$ cannot separate the spherical products. We advise avoiding higher flow rates of $\mathrm{C}_{2} \mathrm{H}_{2}$ to avoid experimental hazards.

\subsection{Reactivity of carbon spheres}

The as-synthesized carbon spheres are inert to HF (48\%). Fig. 7a shows the carbon spheres remaining after dipping them in HF for more than $48 \mathrm{~h}$. This indicates that the carbon spheres are not destroyed and their structure is unaffected. The carbon spheres can be oxidized easily by $\mathrm{KMnO}_{4}\left(\mathrm{H}^{+}\right)$solution. Fig. $7 \mathrm{~b}$ shows a TEM image of the "partially-oxidized" carbon spheres by the $\mathrm{KMnO}_{4}\left(\mathrm{H}^{+}\right)$. Surfaces of the carbon spheres were broken into pieces by $\mathrm{KMnO}_{4}\left(\mathrm{H}^{+}\right)$solution at 80 ${ }^{\circ} \mathrm{C}$, and the whole solid carbon sphere changed to a
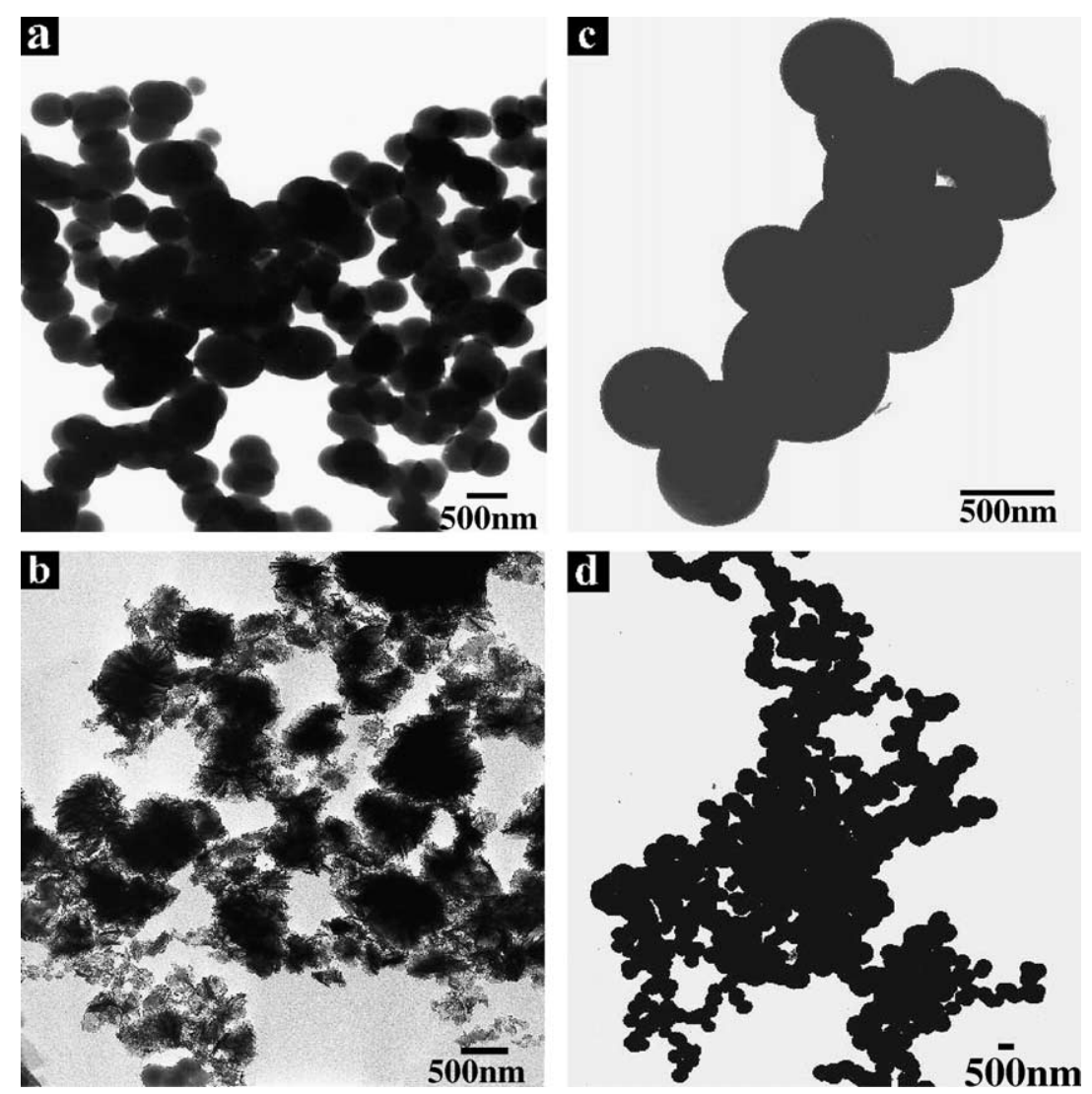

Fig. 7. TEM images of the carbon spheres treated by different chemicals: (a) carbon spheres in $\mathrm{HF}(48 \%)$ solution for $48 \mathrm{~h}$ at $25{ }^{\circ} \mathrm{C}$, (b) carbon spheres in $\mathrm{KMnO}_{4}\left(\mathrm{H}^{+}\right)$solution for $2 \mathrm{~h}$ at $80{ }^{\circ} \mathrm{C}$, (c) in $\mathrm{CS}_{2}$ for $10 \mathrm{~h}$ and (d) in 1-methyl-naphthalene for $10 \mathrm{~h}$. 
loosely structured carbon that we call "carbon flowers". Hence, $\mathrm{KMnO}_{4}$ cannot be used as a solvent medium for carbon spheres.

The as-synthesized carbon spheres of $200 \mathrm{mg}$ were dispersed in $20 \mathrm{ml}$ of carbon disulfide, 1-methylnaphthalene and 1,2-dichlorobenzene, respectively. These mixtures were sonicated for more than $10 \mathrm{~h}$ and then filtered. The filtered organic solutions were dropped onto the copper grids and dried for TEM test. TEM images show that the carbon spheres under suspension not destroyed in the above organic solvents (see Fig. 7c and d). The solubility of the carbon spheres in carbon disulfide is lower than the other two solvents. This investigation can be used to explore the properties of the carbon spheres in organic solvents.

However, the well-defined structures of these carbon spheres cannot be compared with carbon black particles as reviewed by Harris [1], since our materials do not resemble the carbon black, as evidenced from the SEM and TEM images. The carbon black particles have faceted structures and do not have the exact quasi-spherical or spherical structures. We did not observe the oxidation effect in our carbon spheres before and after purification of the samples as revealed by ESR spectra, which will be discussed below.

\subsection{ESR and magnetic properties}

The ESR spectrum of carbon spheres synthesized in this process shows a Dysonian behavior. Fig. 8 displays the ESR spectrum recorded for $600 \mathrm{~nm}$ diameter carbon spheres with $g=2.00$ and a linewidth of $1.85 \mathrm{G}$ with Dysonian line shape indicating the metallic characteristic of carbon nanospheres. The ESR spectra of the catalyst showed resonances corresponding to the $\mathrm{Co}^{2+}$ ions (not shown) whereas that of the reacted catalyst shows no such signals. The diffuse reflectance measure-

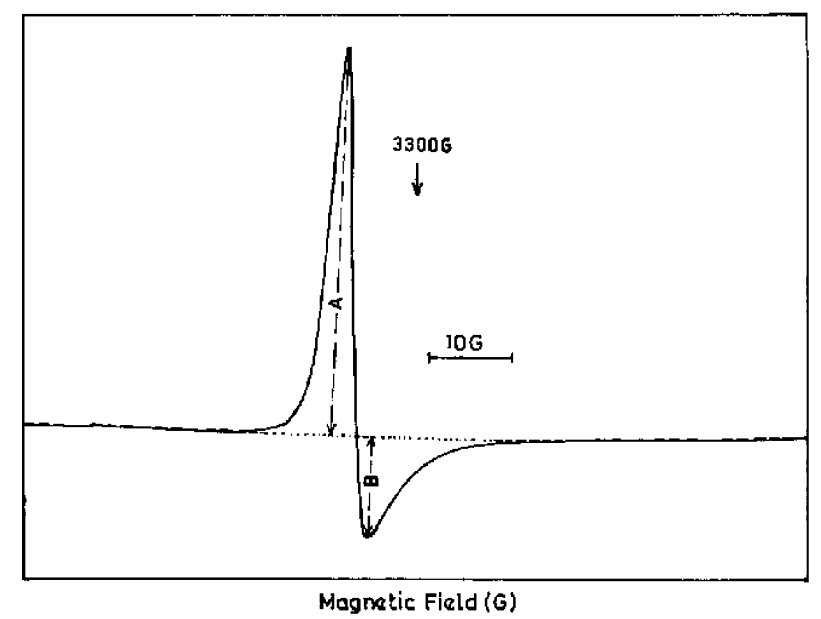

Fig. 8. ESR spectrum of carbon spheres of $600 \mathrm{~nm}$ diameter at room temperature. The central magnetic field is $3300 \mathrm{G}$.

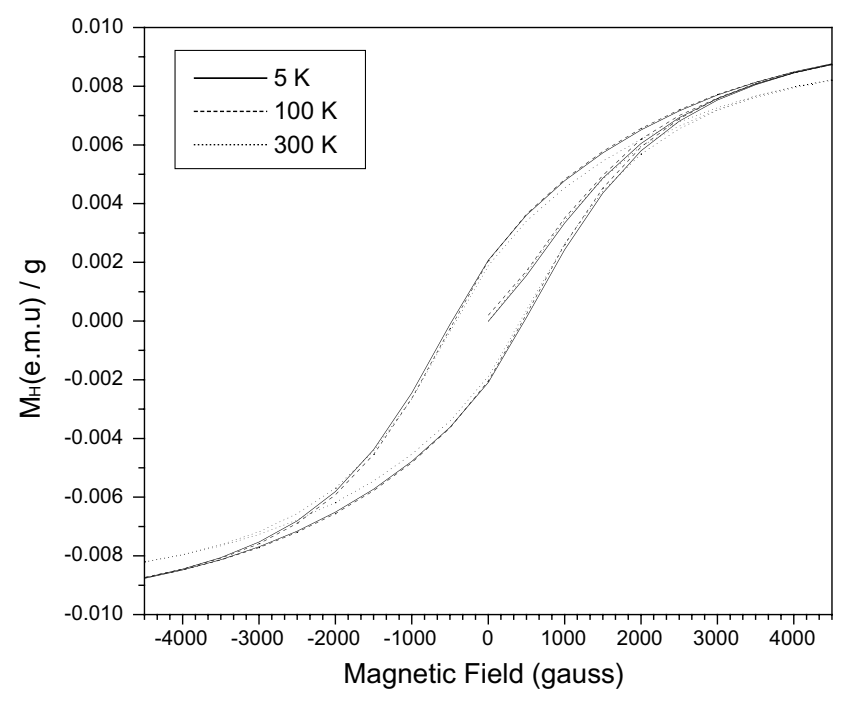

Fig. 9. Magnetization curves of carbon spheres at different temperatures.

ments of the catalyst also showed similar characteristic features for both reacted and unreacted catalysts indicating the complete reduction of cobalt ions into cobalt particles.

The ESR spectra of carbon spheres before and after purification were studied systematically at room temperature. The purification of the carbon spheres was done by immersing and stirring the product in hydrofluoric acid for several hours to remove impurities, if any. The purification makes no difference in their ESR spectral behavior. The ESR spectrum displayed in Fig. 8 , indicates clearly the Dysonian behavior $(A / B=3.76)$ characteristic of conduction electrons. Magnetic hysteresis studies using SQUID have also been performed at three different temperatures as shown in Fig. 9. The curves obtained for the spheres (Fig. 9) at 5 and $100 \mathrm{~K}$ show no deviation in the magnetization behavior with temperature; whereas a little deviation can be seen in the magnetization curve for $300 \mathrm{~K}$. Magnetic parameters have been calculated for the hysteresis loop at $300 \mathrm{~K}$.

The ESR results in conjunction with the magnetization measurements can be understood on the basis of the conduction electrons in the graphitic carbon systems. As the magnetic properties do not change appreciably with sphere size, we performed the SQUID magnetometer measurements for spheres with $600 \mathrm{~nm}$ (Cok4) diameter only. The observed hysteresis loop indicates clearly the non-diamagnetic nature of the carbon spheres.

\section{Discussion}

The present work is the first report on the use of Kaolin as a template for synthesizing carbon spheres with impregnated transition metal (TM) salt $(\mathrm{TM}=\mathrm{Fe}$, 
$\mathrm{Co}$ and $\mathrm{Ni}$ ) as catalysts. Large quantities of carbon spheres can be produced with these catalysts at temperature much lower than those described earlier [3336]. There are five principal species within the Kaolin group, namely, kaolinite, dickite, nacrite, halloysite and metahalloysite [39-41]. As the minerals in the Kaolin group are characterized by a 1:1 tetrahedral:octahedral structure, the halloysite accommodates a mismatch in size between the tetrahedral and octahedral layers by curling with the smaller layer to the inside of the curve. Adjacent layers of Kaolin are separated by a monolayer of water molecules. Consequently, bonding must involve the water molecules between the layers. Since the lack of strong interlayer bonding will not force the sheets into planar stacking, a tubular or spherical structure may form with random stacking and orientation of the layers. In halloysite, this size mismatch and the weak interlayer bonding causes the layer structure to bend. Upon drying, water between the layers of the halloysite is lost, and the curved structure remains unchanged possessing the required porosity. However, the metal ions may be held in the apertures of the tubular or spherical structure of the halloysite.

In the present work, the $\mathrm{Co} /$ Kaolin catalyzes the synthesis of carbon spheres with the apertures of Kaolin as a porous template. $\mathrm{C}_{2} \mathrm{H}_{2}$ was activated by metallic particles and reduced initially to become amorphous carbon. Later, the metal-containing particles embedded in quasi-spherical carbon shells were formed. With increasing reaction times, they melt step by step at relatively higher temperatures and the particles present at the center of the carbon shells become smaller. Such smaller metal containing particles appear in the graphitic layers and can penetrate through the carbon onions [42]. The unclosed graphene layers with open edges in the carbon spheres make the migration of foreign atoms easier than the closed graphitic ones in carbon onions. As the reaction continues, the entire particles may penetrate through the carbon shells leaving pure carbon spheres.

Carbon spheres will be formed from the quasispherical carbon shells by eliminating dangling bonds on the surface of the carbon globules reducing the surface tension. The carbon spheres formed on the surface of the catalyst plate are blown away from the catalyst plate based on their weight fractions by the carrier gas flow. Pure carbon spheres can be obtained from the collecting boat beneath the down stream of catalyst plate. The observed distances between unclosed graphene layers as revealed by HRTEM $(0.33-0.35 \mathrm{~nm})$ indicate the graphitic nature of as-synthesized carbon spheres. The carbon spheres are inert to chemicals, such as HF (48\%). The interaction of $\mathrm{Pt}, \mathrm{CdS}$ and $\mathrm{WO}_{3}$ with carbon spheres has been reported [43]. The open edges of the unclosed graphitic layers are expected to play a key role in their microstructures. The activity of the carbon spheres can be explained due to the eliminating edge sites in the graphitic structure of the spheres. Because of the dangling bonds at the surface of the carbon spheres, a chemical reaction is possible at the open edges of the graphitic layers.

The carbon spheres can be dissolved in carbon disulfide, 1-methylnaphthalene and 1,2-dichlorobenzene, in all of which fullerenes are also soluble. The solubility of fullerene at room temperature in carbon disulfide, 1-methylnaphthalene and 1,2-dichlorobenzene are $6.5,27$ and $33 \mathrm{mg} / \mathrm{ml}$, respectively [44]. The solubility of as-synthesized carbon spheres in the organic solvents, however, is much lower than that of the fullerenes. The solution containing the carbon spheres dissolved in these organic solvents can be used to investigate the different properties of carbon spheres in organic solvents.

The ESR spectra of carbon spheres recorded at room temperature show a narrow Dysonian signal with characteristic $A / B=3.76$ at $g=2.00$ with linewidths, $1 \leqslant \Delta H_{\mathrm{pp}} \leqslant 2.0 \mathrm{G}$. This line can be attributed to the metallic nature of carbon nanospheres. It is comparable with the graphitic carbon structures reported elsewhere [45-47]. Further, the linewidth and $g$-value are very close to the free ion value $\left(g_{\mathrm{e}}=2.0023\right)$ and indicates that this signal may also contains contribution from $\pi$ type defects in $\mathrm{sp}^{2}$ clusters to a small extent. If this is the case, one can also expect a variation in linewidth with particle size and size distribution. The ESR spectra were also recorded for spheres of different sizes at room temperature. The ESR linewidth of the carbon spheres ranges from 1.1 to $2.0 \mathrm{G}$ with decreasing sphere sizes. The carbon spheres denoted by Cok3 $(500 \mathrm{~nm})$ have a linewidth of $2.0 \mathrm{G}$ and those denoted by Cok6 $(1 \mu \mathrm{m})$ have a linewidth of $1.1 \mathrm{G}$. These results are in good agreement with the carbon nanostructures reported elsewhere [46,47]. The smaller linewidths with the increase in sphere size can be attributed to the fact that the increased cluster sizes lead to electron delocalization and hence a stronger wave function overlap and line narrowing [48-50]. However, the ESR linewidths compare well with $\mathrm{C}_{60}$ molecules [51]. The observation that the linewidth of the carbon spheres is not different than that of purified spheres clearly indicates that the spin centers in these carbon spheres are inaccessible to oxidation $[46,47]$.

The SQUID magnetization measurements were made on the carbon spheres at three temperatures 5, 100 and 300 K. As shown in Fig. 9, the variation observed in the magnetization behavior of these carbon spheres with temperatures in the range 100-300 K, can be attributed to the conduction electron mobility. From the observed hysteresis loop, the magnetization parameters like remanent magnetization, coercive field and susceptibilities have been evaluated. The remanent magnetization and the coercive field obtained from the room temperature $(300 \mathrm{~K})$ curve are $0.002 \mathrm{emu}$ and $500 \mathrm{G}$ respectively. The 
initial susceptibility $\chi_{0}$ is found to be $2.4 \times 10^{-6} \mathrm{emu} / \mathrm{G}$ and the value of saturation susceptibility is $3.2 \times 10^{-6}$ $\mathrm{emu} / \mathrm{G}$. The saturation magnetization observed is almost independent of temperature. The order of the susceptibility $\left(10^{-6}\right)$ obtained in the present work clearly indicates Pauli type $\left(10^{-8}\right)$ with dominant Curie $\left(10^{-4}\right)$ spin behavior. So, the susceptibility values obtained in the present work are due to the averaging of both Pauli and Curie susceptibilities and are in good agreement with the values reported elsewhere [47] for carbon nanostructures. These characteristic features of carbon spheres, confirm the ferromagnetic nature and supports the fact that, these materials can be utilized as substitutes in magnetic device applications and also as magnetic materials in ferromagnetic applications [32], where inorganic materials are expected to be highly reactive at high temperatures or at high arcing currents.

\section{Conclusions}

In conclusion, carbon spheres with diameters in the range 400-2000 $\mathrm{nm}$ are synthesized by CCVD in large quantities using Kaolin supported cobalt catalysts for the first time. We performed similar experiments successfully using $\mathrm{Ni}$ and $\mathrm{Fe}$. Using this technique, one can optimize the size of the carbon spheres with the conditions of our report and with high yields produced within the temperature range $750-850^{\circ} \mathrm{C}$. The Dysonian shape of ESR spectra indicates metallic nature for the carbon nanostructure. ESR and SQUID measurements indicate the existence of significant magnetization and indicate the possibility of using these materials for commercial magnetic applications. The highly inert and lightweight mechanical properties of these spheres gives hope that they may be promising as lightweight materials for spacecraft applications.

\section{Acknowledgements}

This work is financially supported by the CTCI foundation of Republic of China (ROC), Taiwan. All the experiments were carried out at Instrumentation Center of the NSC of Taiwan, ROC. The financial support by National Science Council of Taiwan through the grant NSC 90-2113-M-001-045 is gratefully acknowledged.

\section{References}

[1] Harris PJF. Carbon nanotubes and related structures. New materials for the twenty first century. UK: Cambridge; 1999 [chapters 1-8].

[2] Iijima S. J Cryst Growth 1980;50:675.
[3] Kroto HW, Heath JR, O'Brien SC, Curl RF, Smalley RE. Nature 1985;318:162.

[4] Iijima S. Nature 1991;354:56.

[5] Krätschmer W, Lamb LD, Fostiropoulos, Huffman DR. Nature 1990;347:354.

[6] Lee C. US Patent 5,510,098, 1996.

[7] Zhang QL, O'Brien SC, Heath JR, Liu Y, Curl RF, Kroto HW, et al. J Phys Chem B 1986;90:525.

[8] Kukovitsky EF, L'vov SG, Sainov NA. Chem Phys Lett 2000;317:65.

[9] Sinha AK, Hwang DW, Hwang LP. Chem Phys Lett 2000;332:455.

[10] Choi KH, Bourgoin JP, Auvray S, Esteve D, Duesberg GS, Roth S, et al. Surf Sci 2000;462:195.

[11] Calderon Moreno JM, Yoshimura M. J Am Chem Soc 2001;123:741.

[12] Van der Wal RL, Ticich TM, Curtis VE. J Phys Chem B 2000;104:11606.

[13] Shyu Y-M, Chau-Nan Hong F. Diam Relat Mater 2001;10:1241.

[14] Kuznetsov VL, Chuvilin AL, Butenko YV, Mal'kov IY, Titov VM. Chem Phys Lett 1994;222:343.

[15] Banhart F, Füller T, Redlich Ph, Ajayan PM. Chem Phys Lett 1997;269:349.

[16] Zhang M, He DW, Ji L, Wei BQ, Wu DH, Zhang XY, et al. Nanostruct Mater 1998;10:291.

[17] Cabioc'h T, Thune E, Jaouen M. Chem Phys Lett 2000;320:202; Cabioc'h T, Thune E, Jaouen M. Phys Rev B 2002;65:132103.

[18] Sano N, Wang H, Chhowalla M, Alexandrou I, Amaratunga GAJ. Nature 2001;414:506.

[19] Chen XH, Deng FM, Wang JX, Yang HS, Wu GT, Zhang XB, et al. Chem Phys Lett 2001;336:201.

[20] Ajayan PM, Nugent JM, Siegel RW, Wei B, Kohler-Redlich Ph. Nature 2000;404:243.

[21] Jung YJ, Wei B, Nugent J, Ajayan PM. Carbon 2001;39:2195.

[22] Ugarte D. Nature 1992;359:707.

[23] de Heer, Walt A, Ugarte D. Chem Phys Lett 1993;207:480.

[24] Kang ZC, Wang ZL. Philos Mag B 1996;73:905.

[25] Kang ZC, Wang ZL. J Phys Chem B 1996;100:5163.

[26] Kang ZC, Wang ZL. J Mol Catal A: Chem 1997;118:215.

[27] Stöckli T, Bonard J-M, Châtelain A, Wang ZL, Stadelmann P. Phys Rev B 1998;57:599.

[28] Ryoo R, Joo SH, Kruk M, Jaroniec M. Adv Mater 2001;13: 677.

[29] Yoon SB, Sohn K, Kim JY, Shin C-H, Yu J-S, Hyeon T. Adv Mater 2002;4:19.

[30] Wu Y, Qiao P, Chong T, Shen Z. Adv Mater 2002;14:64.

[31] Gutfer-Wurmser F, Konno H, Kaburagi Y, Oshida K, Inagaki M. Synth Met 2002;118:167.

[32] Konno H, Matsuura R, Yamasaki M, Habazaki H. Synth Met 2002;125:167.

[33] Yang JB, Ling LC, Liu L, Kang FY, Huang ZH, Wu H. Carbon 2002;40:911.

[34] Wang ZL, Kang ZC. J Phys Chem B 1996;100:17725.

[35] Inagaki ZC, Kuroda K, Sakai M. Carbon 1983;21:231.

[36] Yamada K, Tobisawa S. Carbon 1989;27:845.

[37] Loa I, Möschel C, Reich A, Assenmacher W, Syassen K, Jansen M. Phys Stat Sol (b) 2001;223:293.

[38] Nicklow R, Wakabayashi N, Smith HG. Phys Rev B 1972;5:4951.

[39] Ivanov AS, Goncharenko IN, Somenkov VA, Braden M. Physica B 1995;213-214:1031.

[40] Dixon JB. Kaolin and serpentine group minerals. In: Dixon JB, Weed SB, editors. Minerals in soil environments, second ed., Madison, WI, Soil Science Society of America, Book Ser. 1, 1989. p. 467.

[41] Bailey SW. Structures of layer silicates. In: Brindley GW, Brown G, editors. Crystal structures of clay minerals and their X-ray identification. London: Mineralogical Society; 1980. p. 6. 
[42] Banhart F, Redlich P, Ajayan PM. Chem Phys Lett 1998;292: 554.

[43] Kang ZC, Wang ZL. J Mol Catal A: Chem 1997;118:215.

[44] Taylor R. Lecture notes on fullerene chemistry: a handbook for chemists. Imperial College Press; 1999. p. 28.

[45] Harbour JR, Walzak MJ, Julien P. Carbon 1985;23:185.

[46] Dunne LJ, Nolan PF, Munnu J, Terrones M, Jones T, Karthirgamanathan P, et al. J Phys Condens Matter 1997;9:10661.
[47] Garaj S, Thien-Nga L, Gaal R, Forro L, Takahashi K, Kokai F, et al. Phys Rev B 2000;62:17115.

[48] Aizawa M, Komatsu T, Nakagawa T. Bull Chem Soc Jpn 1980;53:975.

[49] Sackmann E, Trauble T. J Am Chem Soc 1972;94:4482, 4492 and 4499.

[50] Barklie RC. Diam Relat Mater 2001;10:174.

[51] Kosaka M, Ebbeson TW, Hiura H, Tanigaki K. Chem Phys Lett 1995;233:47. 